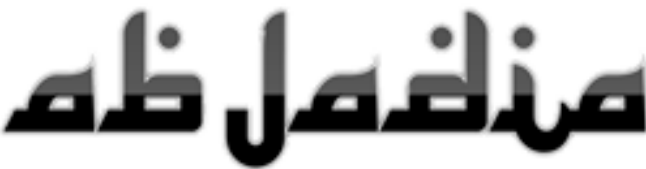

International Journal of Education

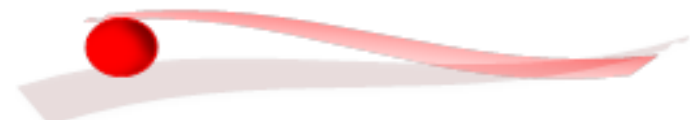

Pi) Publisher

Fakultas Ilmu Tarbiyah dan Keguruan

Universitas Islam Negeri (UIN]

Mualana Malik Ibrahim Malang

Indonesia

2443-0587 - ISSN Online

亮 2528-3979 - ISSN Print

㪶 History Article

t) Received : 17-04-2017

(13) Reviced : 03-05-2017

圈 Accepted : 30-06-2017

\section{doi.org/ 10.18860/abj..v2i1.5311}

http://ejournal.uin-malang.ac.id/index.php/ abjadia/article/view/5311

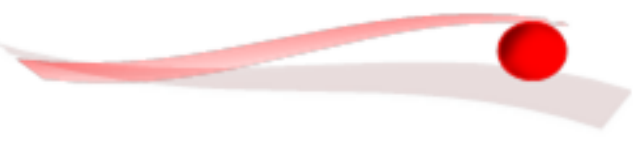

Nurul Hana Mustofa

9 Indonesia

(3)

Universitas Islam Negeri

Maulana Malik Ibrahim

Malang Indonesia

\section{Corresponding Author}

(C) 085866819785

(9) hana.musyofa22@gmail.com

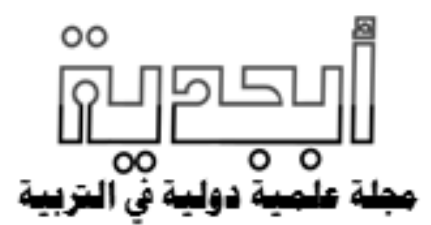

Nurul Hana Mustofa

Indonesia

$$
\text { مشكلات تعليم مهارة القراءة وعلاجها بالمدرسـة }
$$

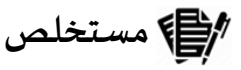

ولا يمكن بغض النظر عن خطط التعليم الحسنة. فالخطط تحصل

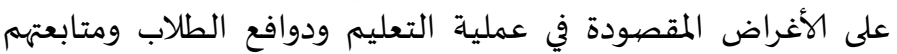

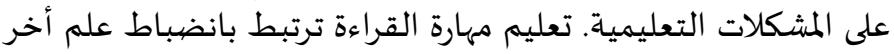

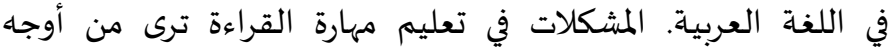

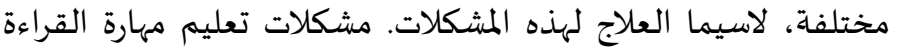

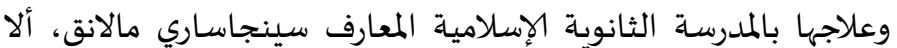

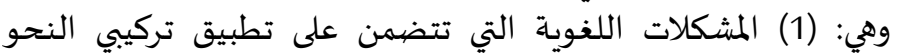

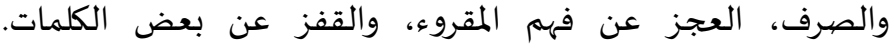

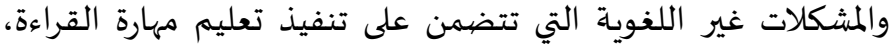

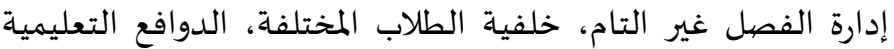

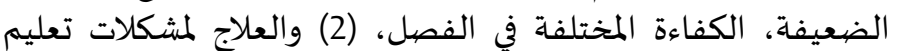

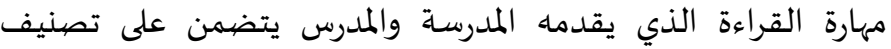

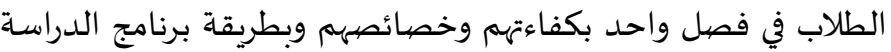
المجموعية، و بطريقة الإدراك بالترابط في بداية التعليم، وبطريقة التخطيط والتقويم

$$
\text { هـ مشكلات التعليم، العلاج لمشكلات تعليم مهارة القراءة }
$$

\section{攅! Abstract}

The success of classroom learning is related to good planning. Planning can achieve learning objectives, motivate students and avoid obstacles in the learning process. The researcher found the learning problem of reading skill in MA Al-Maarif Singosari, namely: (1) Linguistic problematic consisting of problem of application of the theory of Nahwu and Sharaf Rule, the weakness of reading comprehension, and ignoring some words in the text of reading. Non-Linguistic Problematics consist of the implementation of learning in the classroom, less maximal class conditioning, different student backgrounds, the lack of learning motivation to read, the grouping of learners not according to ability, the lack of time provided by the school and the evalution process that does not meet the criteria assessment of reading skills; (2) The solution to solve the problematics of reading skill learning at MA Al-Ma'arif Singosari Malang is the grouping of students according to their ability at the time of acceptance test of new learners, group learning program, motivation in the early apperception of learning, planning and evaluation

@. Problematic Learning, Learning Solutions in Reading Skill 


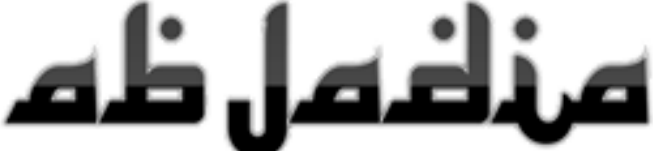
International Journal of Education

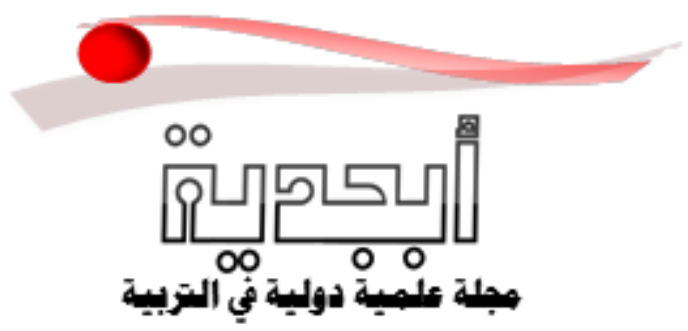

\section{雎" Abstrak}

Keberhasilan pembelajaran di kelas terkait dengan perencanaan yang baik. Perencanaan dapat mencapai tujuan pembelajaran, memotivasi siswa dan menghindari hambatan dalam proses pembelajaran. Peneliti menemukan problem pembelajaran keterampilan membaca di MA Al-Maarif Singosari, yaitu: (1) Problematika Linguistik yang terdiri dari problem penerapan teori Kaidah Nahwu dan Sharaf, lemahnya memahami bacaan, dan menghiraukan sebagian kata pada teks bacaan. Problematika Non Linguistik terdiri dari pelaksanaan pembelajaran di dalam kelas, pengkondisian kelas yang kurang maksimal, latar belakang siswa berbeda-beda, lemahnya motivasi belajar membaca, pengelompokan peserta didik belum sesuai kemampuan, kurangnya waktu yang disediakan oleh pihak sekolah dan proses evalusi yang kurang memenuhi kriteria penilaian keterampilan membaca; (2) Solusi untuk mengatasi problematika pembelajaran keterampilan membaca di MA Al-Ma'arif Singosari Malang adalah pengelompokan siswa sesuai kemampuan mereka pada saat tes penerimaan peserta didik baru, program belajar kelompok, motivasi di saat apersepsi awal pembelajaran, perencanaan dan evaluasi.

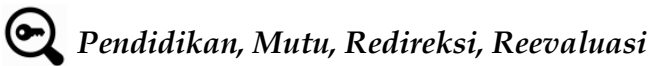

http:// $\quad$ http://ejournal.uin-malang.ac.id/index.php/abjadia/article/view/5311

ومن المهارات اللغوية ما يكون منتجة (productive) وما يكون تقبلية(receptive) ـ فاللغوية المنتجة هي

مهارة الكتابة ومهارة الكلام. وتشتمل التعبير التحريري والشفوي على التعبير الوظيفي والإبداعي. فالتعبير الوظيفي يحقق اتصال الناس بعضهم ببعض، لتنظيم حياتهم وقضاء حاجتهم. والتعبير الإبداعي ينقل المشاعر والأحاسيس والخواطر النفسية إلى الآخرين بأسلوب أدبي مشوق ومثير ككتابة الشعر والتراجم والتمثيليات والقصص الأدابي (شحاته 1993). وأما اللغوية التقبلية هي مهارة القراءة ومهارة الاستماع. وترتبط مهارة بمهارة أخرى، ولا سيما بمارة القراءة فتحتاج إلى كل المهارت في استيعاب مهارة اللغة العربية بالصحيحة.

مهارة القراءة هي مهارة لغوية أسـاسية يجب أن يستوليها الطلبة إلى جانب مهارة الاستماع ومهارة الكلام ومهارة الكتابة. هذه هي جدير بالطالب استيعابها عند تعلم اللغة الأجنبية. وتهتم مهارة القراءة بالأمرين الأول الوقوف على رموز اللغة التي تحتوي على علاقة المعنى الملائم بالرمز المكتوب، واستخدام سياق اللغة حتى يقدر على انتخاب المفهوم الدقيق والمهارة لتفريق أصوات الحروف وغير ذلك. والثانى قدرة الفهم التي تحتوي على استنباط الفكرة الأسساسية في النص وهي استنباط الأفكار الجزئية والقدرة على التحليل والنقد في أثناء القراءة وغير ذلك (الخطيب 2003). 
والتعليم عملية قام باه المعلم للحصول على الهدف المقرر. يتعلق التعليم بالعوامل كالهدف والمواد المدروسـة وطرق التدريس والمعلم والوسائل الدافعة لله. والتعليم كذلك عملية قام بها المعلم لإيصال المعلومات والمهارات إلى أذهان التلاميذ (ينوس 2007).

فأصبحت مهارة القراءة القائمة في بعض المدارس والمعاهد معتمدة على عرض الكلمات التي يعتبرها الطلبة كلمة جديدة. وإن الحصول على قدرة الفهم عند عملية القراءة ليست سهولة. هذا يدل على أن بين مهارة القراءة وقدرة الفهم نقطة نائية. وللحصول إلى تلك النقطة النائية سبل يمكن للطلبة أن يسلكها. إذا مهارة القراءة مهمة لدي الطلبة وغاية رئيسية في تعليم اللغة العربية بالمدرسة. فيحتاج مدرسو اللغة كل ناح من النواحى المتربطة بتعليم اللغة العربية خاصة بطريقة القراءة في التعلم (مدكور 2010). وعلى هذا فإن مهارة القراءة تساعد الطلبة إحساسهم اللغوي وتذوقهم لمعانى الجمل. وعند تعليم اللغة العربية مار على الثانوية والكلية فالاهتمام بهذا جاد بسبب القضايا المهملة على المستوى السابق، حتى لم تصل إلى الحل الصحيح، ولم تجر للعثور على السبب الرئيسي لها. إعتمادا على هذا يمكن التماس الحلول لهذه المشكلات من خلال الإحالات من الطلاب والمعلمين. ويمكن الاطلاع على المشاكل من خلال المراحل الأولية في شكل تحليل الظروف التي تتعلق بالقضايا ولا تقال لها المشكلة الحقيقية، وإذا تتحقق هذه المشكلة فهي المشكلة التي أصبحت عقبة أساسية لتعليم اللغة العربية. وجرت هذه المراحل للعثور على المشكلة الحقيقية حتى يكتسب العلاج لها (Saidu 2006). في الواقع كل الطلاب لهم الفرق بين الواحد والأخر من جانب المادي، والعقلية، وسبل الاستجابة أو تعليمهه الأشياء الجديدة. وفي سياق التعليم، كل الطلاب لهه مزاياهم وعيوبهم في استيعاب الدرس (Asrori 2008). فالطلاب يواجههم المشاكل في دراستهم، ومثلها في تطبيق تركيبي النحو والصرف حينما أمر المدرس طالبا أن يقرأ النص العربي أثاء الدراسـة، والعجزعن أداء المعنى، فمثل أخر عندما يترجم الطالب النص العربي إلى اللغة الإندونيسية غير مناسب بما يرجى في الناص. وهذا هو أيضا يتوافق بتعليم مهارة القراءة التي لديها مشاكل التعليم. والقضايا المهملة في البداية أساس للبطئ الجاد عندما تجري في المستوى العليا من التعليم الثانوي والتعليم العالي. وينبغي وجود العلاج لهذه المشكلات، فيحصل على مهارة القراءة العلاج الصحيح عنها. 
بناء على هذه المشكلات، أدى الباحث الملاحظة على عملية تعليم اللغة العربية في القسم العاشر 2 بالمدرسة الثانوية الإسلامية المعارف سنجاساري مالانق من خلال الملاحظة والمقابلة المباشرة من أجل

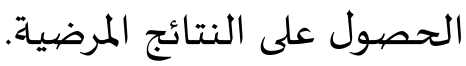

\section{[Q]}

يهدف هذا البحث نيل الوصف العميق عن مشكلات تعليم مهارة القراءة بالمدرسة الثانوية الإسلامية المعارف سنجاساري، ونيل الوصفية بشكل الكلمات المكتوبة و الوثيقة التي يلاحظها الباحث كما كان. و فيه استخدام المنهج الوصفي الكيفي ليبين الباحث المشاهدات المناسبة بتصيير شيئ لموضوع هدفا

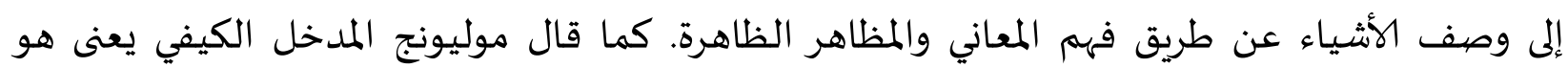
الشيئ من إجراء البحث الذي يحصل باه البيانات الوصفية بوجود مراقبة الكلمة والمشاهدة. وبعبارة أخرى قول بوغدان وتايلور أن المنهج الكيفي إجراء البحث الذي يحصل على جمع البيانات الوفصية سواء كانت كتابة أو لسانا من الإنسان والفعل(Moleong 2007).

واستخدم الباحث هذا المنهج الكيفي تفهيما وتفسيرا لمعانى في الواقع وعملية التعليمية تاريخيا وسياقيا. وعندهم هذا المدخل يوجه في الأرضية والنفسية كاملا وتاما. لذلك لا يجوز عزلة النفسية والمنظمة في الفرضية بل ينظر من الكاملة والتامة أيضا (Arikunto 2010). ثم يبحث الباحث في الحقائق التي تتعلق بمشكلات تعليم مهارة القراءة في القسم العاشر 2 بالمدرسة الثانوية الإسلامية المعارف سينجاساري مالانق. إضافة إلى جانب الأخر، ينبغى على الباحث أن يحضر في المكان لكي يحصل على

$$
\text { مكانير الوصف الحقيقي. }
$$

مكان البحث المختار فيه هو المدرسة الثانوية الإسلامية المعارف سنجاسارى مالانق في القسم العاشر 2 واختيار هذا المكان لأداء البحث بأسباب رئيسية هي: 1) إن هذه المدرسة إحدى المدارس المشهورة في ولاية سنجاسارى مالانق التي تجري فهها عملية تعليم اللغة العربية خاصة في مهارة القراءة؛ 2) إن هذه المدرسة مشهورة بالمتخرجين الذين يستطيعون قراءة الكتب العببية؛ 3) إن هذه المدرسة مشهورة بالمدرسة السلافية التي تقدم على قراءة الكتب العربية لاسيما القسم العاشر 2. مصادر البيانات 
ومصيادرها تشتمل على جميع المعلومات والأخبار التي توجد من مصيادر البيانات. كما قال سونارطا إن البيانات تشكل برهانا لعلاج مشكلات البحث (Sunarto 2001). وعند لوفوند مصادر البيانات في البحث الكيفي مأخوذة من الأقوال والأحوال. وتدخل فيها أنواع البيانات الإضيافية مثل الوثائق والملاحظة والمقابلة. سواء كان تحصيلها بوسيلة المباشرة بين الباحث والطلبة ومدرس اللغة العربية. فمصيادر البيانات المقصودة هنا: (1) مصادر البيانات الرئيسية هي التي حصلت فيها البيانات ( Sukandarramidi Bungin ( n.d (2)؛ مصدر البيانات الثناوية. هو مصدر البيانات الثانية بعد مصيدر البيانات الرئيسية (2001

\section{أسلوب جمع البيانات}

استخدم الباحث ثلاث طرق مناسبة لجمع البيانات عن مشكلات تعليم مهارة القراءة وعلاجها. وهي: (1) الملاحظة وهي وسيلة يستخدمها الإنسان العادى في اكتساباه لخبرات والمعلومات حيث يجمع الخبرات من خلال ما يشاهده أو يسمعاء(جابر n.d.)؛ (2) المقابلة المتعمقة، وهي الطريقة العملية لجمع البيانات بوسيلة الأسئلة والإجابة بين الشخصين فأكثر في مجلس واحد مواجه. وتنقسم المقابلة على ثلاثة أقسام: (1) المقابلة الحرة هي لا حمل السائل إرشاد الأسئلة في عمله؛ (2) المقابلة المنظمة هي حمل السائل إرشاد Arikunto ( الأسئلة في عمله؛ (3) المقابلة الحرة والمنظمة هي التركيب بين المقابلة الحرة والمقابلة المنظمة

عرفه فاطون (Faton) بعملية تنسيق البيانات وترتيبها على صيغة الطريقة المعينة. ثم يأكده لكي موليونج تحليل البيانات بعملية تشكيل البيانات وترتيبها حسب الشكل أو الصيغة المعينة حتى تظهر صورة معينة (Moleong 2007). وتحليل البيانات في البحث نشاط مهم جدا ويتطلب الدقة العميقة عن التفاسير من الباحثين. وهو عملية مستمرة يتطلب التفكير المستمر وطرح الأسئلة التحليلية، والكتابة، والملاحظة المختصرة على طوال البحث(Crewell 2013). وهذا يجرى عند تخطيط المشكلة وتصريحها وإجراءاتها في ميدان البحث حتى عملية كتابة البحث. ولكن في البحث الكيفي الوصفي تخصيص التحليالات حين يجري عملية البحث وجمع البيانات.

فإن طريقة جمع البيانات وطريقة تحليلها لا يسهل فصالها بل طريقة جمع البيانات وتحليلها تجري معا، يمعنى الباحث أن تحليل البيانات ينبغى عملها مع جمع البيانات ثم يستمر التحليل بعد تمام جمع 
البيانات (Gunawan 2013). وبتلك النشاطات المذكورة كون البيانات من البحث الكيفي الوصفي غالبة منتشرة، فينبغي تبسيطها كي تفهم بالسهولة.

التثليث

بين ديني أندريان (Deni Andriyan) يستخدم الباحث التثليث لتصحيح البيانات. وبمعنى أخر التثليث هو تصحيح البيانات بطريقة أخرى تنتفع نتائج المقابلة على المبحوث. ويجري التثليث باستخدام التقنيك المختلف وهو المقابلة والملاحظة والوثائق، ويكون التثليث زائدا في البيانات (2007 Moleong). فعند نسوتيون (Nasution) الاضافة إلى هذا التثليث يمكن ان يكون مفيده أيضا للتحقيق في صحة تفسير البيانات (Nasution 2003). دينزين مولونغ يميز التثليث إلى أربع من خلال الاستفادة من استخدام

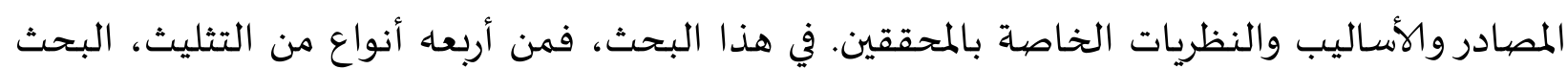
استخدم الامتحان من خلال الاستفادة من الموارد. التثليث عن طريق المصادر يقارن و يحقق من وراء درجه الثقة اي المعلومات المكتسبة من خلال الوقت والأداوات المختلفة في البحث الكيفي كما قاله الباتون (Paton).

أما بالنسبة للثقة لتحقيق ذلك، ثم اتخذت الخطوات التالي: (1) المقارنة بين بيانات الملاحظة ونتائج المقابلة؛ (2) مقارنة ما يقوله الناس في العام مع ما يقال مجردا؛ (3) مقارنة ما يقوله الناس عن حالة

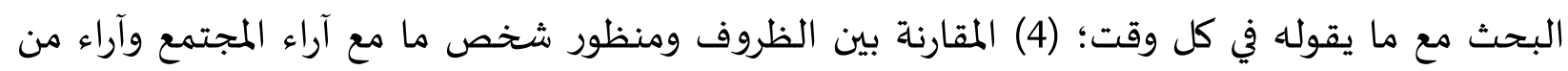
يختلف الفئات؛ (5) المقارنة بين نتائج المقابلات مع محتويات الوثائق.

فأما تصحيح البيانات في هذا البحث يجري على خطوتين: (1) يقرأ و يطالع الباحث البيانات المحصولة كافة بأساس أدلة المقابلات؛ (2) يطالع ويتذكر الباحث البيانات المحصولة كافة بأسس أدلة الملاحظات.

نتائج

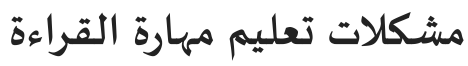

إن عملية التعليم تمكن أن توصف بخطط تنفيد التعليم. أما المشكلات المواجهة عند تنفيذ تعليم مهارة القراءة هي هيئة الفصل و تركيز الطلاب على المواد المفصلة. هناك عوامل أخرى تؤثر علي هذه المشكلات العامة. استخدام النظام الفصلي غير المتجانس، فكفاءة الطلاب لم تكن في مجموع واحد 
بطبيعة واحدة. إذ اجتمع التبيعة المتنوعة في مجموع واحد. كما اجتمع تبيعة الطلاب بالعربية مع الطلاب بالتبيعة الأخري. فهذا سبب في حواجز تنفيد تعليم مهارة القراءة فيه. ولكن هذه الظواهر تمكننا أن نقول الشكر إلى المعهد الإسلام الذي يقع جوانب هذه المدرسـة. ومعضيم الطلاب يسكنون في المعهد 70\% تقريبا. في تقوبم مهارة القراءة

أسـاسـا على الملاحظة، فعملية التقويم التي قام به المعلم توجد المشكلات، ولكن هذه الأمر قد يمكن التغلب على حلها وقد يمكن الإهمال عليها. فالتقويم بشكل قراءة النص بغير حركة في أخر الكلمة ليتدرب الطلاب تتبيق التراكيب. فتكنوليجيا قد يكون مواجها وقد يكون التقديم أمام الفصل. باستخدام KKM الأعلى يعني 80 في مادة العبية ولأها من المواد الرئيسية في القسم العاشر 2 في المدرسة الثانوية الإسلامية سنجاسارى مالانغ مدرس يؤدي إعادة الامتحان لكل طالب لم تلتقي قيمته الحد حتى تصل إلى القيمة القصوى. إذا كان الطلاب الذين لا ينجحون في الامتحان فالإعادة عليهم واجب حتى نالوا النتيجة

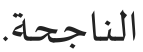

\section{في الدوافع على تعلم مهارة القراءة}

تعلم استعمار اللغة الأمية هو شيئ مهم جدا في حياه الناس. لأههم يعتمدون علي المهارات اللغوية المحتاجة إلى حياتهم ويمكن أن تكسب الرغبات. كذلك إن كانت أحوال نفسهم غاضبة أو سعيدة وهكذا يعرفها الأخرون. كل ما يمكن معرفتها عندما يعبر الناس باللغة الصحيحة. إن مادة اللغة العربية مادة رئيسية في هذه المدرسـة، فلذلك ينبغي علي أن نمارس اللغة العربية وتدخلها مهارة القراءة. وهذا يدل على أن دافع تعلم مهارة القراءة ضعيف. تطبيق النحوووالصبرف قراءة الأدب باللغة العربية يتطلب مجموعة من القواعد أو النحوية التي يتم تعيينها (قواعد اللغة العبية)). القواعد التي تتكون من قواعد الصرف وقواعد النحو مفيدة للغاية في تحديد الجملة التي لا شكل لها أي بدون الحركات. علي سبيل المثال كلمة في كلمات تتكون من 5 أحرف، ثم الحرف الأول إلى الحرف الرابع هي وظيفة العلوم الصرفية، وأما الحرف الأخر هو وظيفة العلوم النحوية. التالي علي حد سواء العلوم التي تشير إلى استخدام اللغة العربية بشكل جيد ، بناء على ذلك فإن هذه الأمور أي قواعد الصرف والنحو لها أثار في فهم مضمون محتوي الأدب العربي وليس فياء التباس. ويتطلب فهم المقروء 
فالعنصوران اللذان سبق ذكرهما يمكن للمتعلمين أن يتخذواها أي يعلموها إلى الطلاب بعميق ليكونوا قادين علي إعطاء شكل صحيح في نص القراءة ويمكن أن يفهموه أيضا. وأنه يناسب التعبير عن الغربيين الذين يقولون أن العرب لزمتهم القواعد ثم يقدرون أن يقرؤوا النص العربي صحيحا كان وفهما.

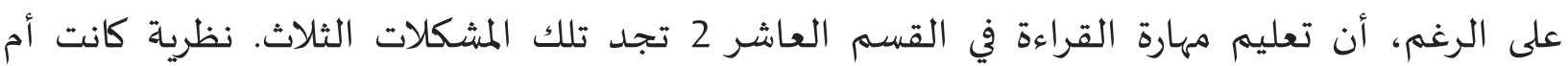
تنفيدية وسيطرة على دوافع فهم النصوص التي لا تزال المشكلات. فهم المقروء أوعجز الطلاب عن أداء المعنى

إحدى المواد التعليمية هي اللغة العربية التي يصعب بها الطلاب فهما مقروئيا، بسبب صعوبة تحليل الإعراب وترتيب الموضوع، والتركيب بين اللغة العربية مع الجمل في كثير من الأحيان اختلفت باللغة الإندونيسية. ثم تختلف خلفية الطلاب، ومعظم الطلاب ما زالت تتاثر بلغة الأم أي إندونيسية حتى الحين الاعنين

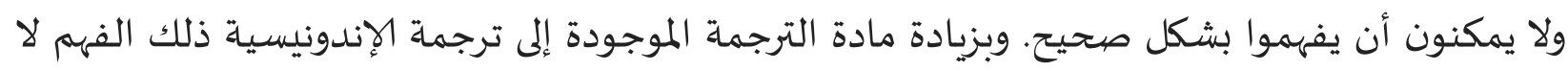
يقدر الطلاب أن يترجموا بشكل صحيح. بناء على نتيجة الملاحظة، دلت إلى أن اختبارا شفويا لها مشكلات التي يواجهها الطلاب. المشكلات هنا وضع الحركة في أواخر الكلمات أي الإعراب لهم مشكلات مهمة. كقراءة الكلمة الواجبة بالكسرة في

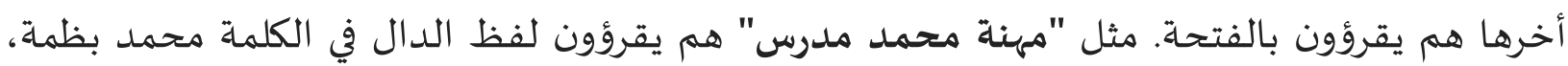

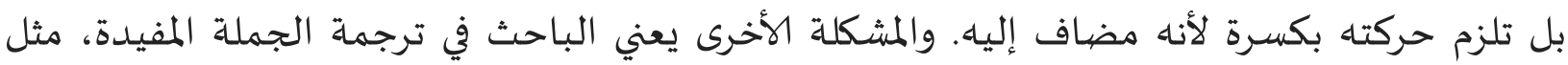

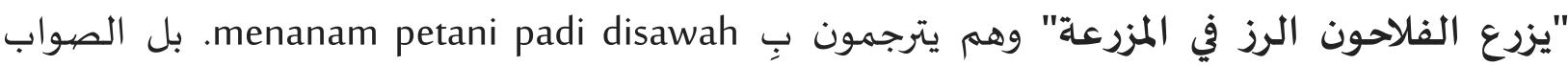
petani menanam padi disawah

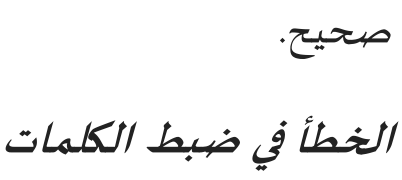

الخوف في تعلم اللغة قد يصيب إلى متعلميها إنجيليزية كانت أو عربية. كما وصفه الطالب في القسم

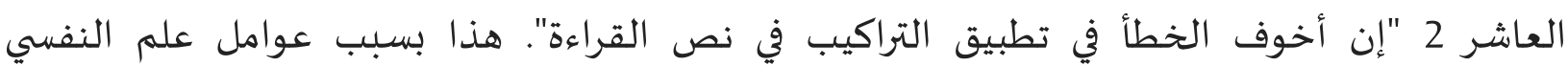

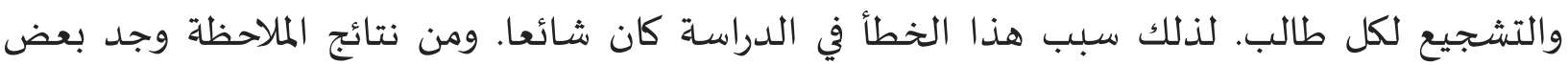
الطلاب يصعبون أن يقرؤوا أواخر الكلمات أي الإعراب لأهم ينقصون من القواعد النحوية والصرفية. فمن نتائج الملاحظة فالطلاب يخافون أن يطبقوا تركيب النحو في أخر الكلمات إذا كانت قراءتهم خطأ. فهذا سبب بطئهم في القراءة. القفزعن بعض الكلمات 
قد تهتمل بعض الجوانب المتعلقة بالمفردات التي لا تعلمها في معنى معين. وصدق القول هذا عندما يلاحظ الباحث في الفصل والنظرية التي قدمها الباحث. فهذه الظواهر أي المشكلات قد أصابت إلى كل من الطلاب الذين يتعلمون اللغة. وبعض الطلاب يقرؤون النص العربي أمام الفصل والباحث يستمع صوتهم فيجد الباحث بعض الكلمات غير المقروءة بسبب لا يقدرون أن يوقعوا الحركة في الكلمة. فهذا السبب من ضعف كفاءة الصرف.

\section{نقصيان الوقت للقراءة}

مهارة القراءة تحتاج إلى الاهتمام والوقت مرات إذ يريد الطلاب إتقان اللغة. وفضلا على ذلك، تحتاج إلى فترة طويلة، لذلك استخدام الوقت ينبغي علياء كفاءة، ويجب ذلك الاستخدام حسن الموقتة في الدرس حتى لا يكون الطلاب مخيبين في دراسة مهارة القراءة. والوقت الموقتة لمادة اللغة العربية من وزير الشؤون الإسلامي نالت أربع حصات أسبوعيا. ولكن، في هذه المدرسة أعطت إثنا سـاعات فقد. لأن المواد المحلية في هذه المدرسـة كثيرة جدا، فلذلك من جهاة المدرسـة تنقص الوقت لمادة اللغة العربية. فمن هنا ظهرت أن الوقت للقراءة ينقص أيضيا. تصينيف الطلاب

إحدى الإستراتيجيات التي تدعم النجاح في التعليم هي ربط الطلاب بتبيعتهم. وإذا يمكن أن تجعل هذه الإستراتيجية وقت القبول فاتخاذ الإجراء للتعامل مع الحواجز التعليمية الواقعية أصغر محتاجة. ومن تنائج المقابلة مع مدير المدرسـة ومعلم اللغة العربية أن الاختبار لدخول المدرسة أول مرة قراءة القرءان وكتابته فقط. ومما يدل على نتيجة الملاحظة أن بعض الطلاب لا يتعاونوا ولا يدافعوا بعضهم

والخلاصة الموقتة من وصف الظواهر التعليمية أي من نتائج المقابلة والخلاصة والوثائق التي وجدها الباحث أن المشكلات ليست من عنصيور نفساه بل المشكلات تحتوي على كل من العناصر التعليمية. فحصل هذا البحث على أن من مشكلات تعليم مهارة القراءة في القسم العاشر 2 بالمدرسة الإسالامية المعارف سينجاسارى مالانق هي المشكلة في تنفيذ مهارة القراءة وحواجزه، و المشكلة في تقويم مهارة القراءة، والمشكلة في الدوافع على تعلم مهارة القراءة، والمشكلة في تطبيق النحو والصيرف في القراءة، والمشكلة في فهم المقروء، والمشكلة في الخطاء في ظبط الكلمات، والمشكلة في القفز عن بعض الكلمات، والمشكلة في نقصان الوقت للقراءة، والمشكلة في تصنيف الطلاب. 
علاج هذه المشكلات

البونامج من جهة الملدربة

فمن جهة المدرسة برامج تعليمية ينظمها مدير المدرسة والمدرسون بحيث الطلاب الذين واجهوا المشكلات أو الحواجز التي تمكنت متابعتهم هذا البرنامج، ويمكن تصنيف الطلاب الجدد في الفئات المناسبة بقدراتهم في فصل واحد. والبرنامج هي كما يالي : الأول: تخيير الطلاب الجـدد تصنيفا باختبار قراءة القرءان في فصل واحد ويمكن أن تجمع طلابا بقدر تبيعتهم. وبناء على هذا المدرسة تري أيما الطلاب يستطيعون باللغة العربية وبالانظباط الأخر. وكما قال مدير المدرسـة سيبدأ من هذا العام البرنامج الاختباري تصنيفا للطلاب في فصل واحد بقدر عقولهم أي قدرتهم لعلاج المشكلات التعليمية. وهذه الحالة تدل على سبب المشكلات التعليمية طوال الزمان في المدرسة الثانوية الإسلامية المعارف مالانق.

والثاني: صنعت المدرسة برامج التعلم (الدراسة المجموعية) بعد انتهاء الأنشطة التعليمية لكل لكل المواد الدراسية، وليست استثناء أيضا المادة العربية. وهذا البرنامج للطلبة الذين لايستغنون الحواجز والعلاج في تعلمهم. للغة العربية هناك مجموعات دراسية معا بعد تعلمهم في الفصل قراءة كانت أو كلاما أو كتابة. والدراسة المجموعية هي البرنامج للطلاب استقلالا في تعلمهم. قد لا يزال الطلاب الذين يجيؤون إلى المدرسة ثم يعودون إلى ديارهم دون الاختلاط والدراسة مع أصدقائهم ليزداد علمهم. وكل شخص مختلفة تبيعاتهم ولكن بوجود الدراسة المجموعية يمكن أن تبادل أراءهم. الذين يرجعون سارعا إلى ديارهم بعد أن يدرسوا فالأن لزم عليهم أن يتبعوا البرنامج وهو مؤكد للطلاب ينالون نتيجة الاختبار الأدنى على حد ما.

البرنامج من جهة المعلم

يدفع معلم اللغة العربية إعطاء التوجياه الجيد دائما، إما الدافع لتعلم اللغة العبية وتشجيع لممارسة مهارة القراءة ممفردا كان الطالب أو مجموعيا، ولأن بالقراءة سيفتح باب أعلام العلوم الأخرى. الأول: الإدراك بالترابط في بداية التعليم. شرع المعلم تعليم مهارة القراءة بإعطاء الدوافع الحسنة للطلبة. ودوافعه أن يأمر الطلاب أن يتعلموا اللغة العربية لأنها لغة دين الإسلام، لغة القرءان، لغة لمفاتيح العلوم الشرعية الإسلامياة. وكان الإدراك بالترابط في بداية التعليم مهمة لدى الطلبة. وعلى الرغم، ففي الممارسة العملية فإن الإدراك بالترابط في بداية التعليم ليست سهلة. فالصعوبة هنا ليست بسبب عدم إتقان المعلم على الإدراك بالترابط في بداية التعليم فقط، ولكن بعض المعلمين يظنون أن الإدراك 
بالترابط في بداية التعليم يؤثرها صغيرا، ولذلك، قل المعلمون يؤدون الإدراك بالترابط في بداية التعليم عند دخول الفصل. ومن نتائج الملاحظة أيظا، دال على أن المعلم يؤتي الإدراك بالترابط قبل تعليماه مادة مهارة القراءة.

والثاني: تخطيط التقويم. وأعلن المدرس قبل تنفيذ الاختبار الأسبوعي ليستعدد الطلاب أنفسهم يقدرون على إجابة الأسئلة الصحيحة حتى نالوا النتيجة الأعلى حتى لايكونوا معادين بسبب الاختبار الفجئي. فالنظام هنا لهيتم الطلاب دراستهم وليجتهدوها. والخلاصة المؤقتة من وصف الظواهر التعليمية أي من نتائج المقابلة والخلاصة والوثائق التي وجدها الباحث أن العلاج الذي يقدماه المدرسة والمعلم هو تخيير الطلاب الجدد تصنيفا في فصل واحد، وصنعت المدرسة برامج التعلم (الدراسـة المجموعية)، الإدراك بالترابط في بداية التعليم تخطيط التقويم.

\section{فُبْز مناقشَة}

وفقا لولاية اللائحة الحكومية رقم 19 سنة 2005 عن معايير التربية الوطنية التي لازمتها النشأة هي العملية الموحدة. العملية الموحدة هي المعايير الوطنية المتعلقة بتنفيذ وحدة التعليمية لتحقق كفاءة المتخرجين الناجحين. وتتضمن العملية الموحدة على الحد الأدنى من معايير عملية التعلم في وحدة التعليم الابتدائي والثانوي في جميع أنحاء الأراض بالجمهورية إندونيسيا. وهذه العملية تنطبق على معايير التعليم الابتدائي والثانوي في الرسمي، إما على النظام أو إما على المجموعاة من نظام القروض الدراسية. وتشمل العملية الموحدة على التخطيط لعملية التعلم، والتنفيذ لعملية التعلم، وتقويم نتائج التعليم، وإشراف عملية التعليم لتنفيذ عملية التعلم فعالية كانت أو كفاءة. فعملية القراءة على أنها علوم معريفية ولا يمكن لأحد أن ينكر عليها. هذا النشاط كثيرة مزاياها، على الأقل هي السهولة أن يعملها في أي وقت وفي أي مكان دون أن يرتبط بالمكان والزمان. وتنطبق هذه الحالة على جميع اللغات في العالم، وخاصة في الأدب العربي. وتعتقد العربية حتى تكون لغة علمية. وهي مفتاح لكشف واستكشاف العلوم والحضارة العربية الإسلامية. وفضلا عن ذلك فإن ميزة اللغة العربية تزدادت برعاية الحفظ على نقاء القرآن. جمال لغتاه لا مثيل لها وليس هناك من قدر على أن يؤتي بمثله. وقال هداية نور وحيد أنه يذكر تعليم اللغة العربية في إندونيسيا له المشكلات فسبب هذه المشكلات على أربعة عوامل: (1) عامل اللغة نفسها؛ (2) العوامل الاجتماعية؛؛ (3) العوامل النفسانية؛؛ (4) العامل التربوي (Wahid 1988). ويستند الباحث النظرية التي قدمها نانداغ شريف هداية في بحثـه حتى 
يمكن أن يستخدمها الباحث في هذه المناقشة، وهي تصنف المشكلات اللغوية إلى ثلاثة أجزاء: (1) العوامل اللغوية نفسها؛ (2) العوامل من التدريس؛ (3) العوامل الدافعة بدعم التعليم(Hidayat 2012). مشكلات تعليم مهارة القراءة فيه المشككلات اللغوية

تعليم اللغة العربية له المشكلات لاسيما في مهارة القراءة. والمشكلات من نفس اللغة تسمى بالمشكلات اللغوية، وأما من من داخل اللغة فهي تسهى بالمشكلات غير اللغوية. فالمشكلات اللغوية التي وجدها الباحث في القسم العاشر 2 كما يلي: (1) المشكلة في تطبيق تركيبي النحو والصرف أو الخطأ في ضبط الكلمات؛ (2) المشكلة في فهم المقروء؛ (3) المشكلة في قفزبعض بـ الكلمات. من الجلى أن المشكلات التي يواجهها الطلاب في القسم العاشر 2 المشكلة في تطبيق تركيبي النحو والصرف أو الخطأ في ضبط الكلمات على نص القراءة العربية بسبب الطلاب لايمارسون ويخافون القراءة عادة. إضافة على ذلك، كثرة أبواب الصرف والنحو تسبيهم بطيئة على تطبيقها. وفي مشكلة فهم المقروء، معانى شاملة متنوعاة فتختلف باللغة الإندزنيسية. تعدد المعانى الحقيقية والمجازية في العربية تعطي المتاعب إلى الطلاب عندما يفهمونها ويترجمونها إلى اللغة الإندونيسية. وفي مشكلة قفز بعض الكلمات، إذ مهارة القراءة تتطلب بقراءة سريعة ففيها بعض الكلمات المهملة التي تصعب الطلاب معنى. ويربط الباحث في هذا التحليل بين مشكلات تعليم اللغة العربية العامة وبين مشكلات تعليم مهارة القراءة خاصية. المشككلات غير اللغوية الأول: المشكلة الاجتماعية

وهي خلفية الطلبة المختلفة (توفيق 2000). ويسهل المتخرجون من المدرسة الابتدائية الإسلامية عندما يتعلمون مهارة القراءة لأهم يتعرفون اللغة العربية قديما. جانبا على ذلك، الطلاب يسكنون في المعهد الإسلامي لهم المزايا في مهارة القراءة ويمارسون قراءة النص العربي كل يوم في معهدهم. فهذه الوقائع تسبب إلى بطيئة التعليم في الفصل ويختلف هذا الأمر بالمستخرجين من المدرسة الابتدائية الحكومية. حتى تقال خلفية الطلاب والبيئة الاجتماعية تؤثر إلى كفاءة مهارة القراءة.

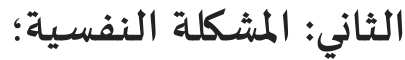


الدوافع التربوية تؤثر إلى سير التعليم، فالطلاب لهم الدوافع تسهلوا لانقياد عملية التدريس العربي في الفصل. فمشكلة هذه تصيب إلى الطلاب في القسم العاشر 2 مادة مهارة القراءة. وبعضهم يذكرون الدوافع تحدد إلى اتباع التعليم فقط ليست لهم الدوافع تدافعهم إلى نشيط التعلم. وفضلا على ذلك، بعضهم يكرهون مهارة القراءة بسبب صعوبة التراكيب وتطبيقها في نص القراءة. وهذا يدل على أن دوافعهم خفيفة وضعيفة.

والتجميع هو مجموعة من المتعلمين على أسس خصائصهم(Imron 1989). ويجب تصنيف هذه الخصائص لكي تكون في نفس الحالة. ومن وجود هذه الشروط مخففة من منح الخدمة عليهم. هو مشترك بالشبك. ومن المحاضر قال إلى أن تصنيف الطلبة عقد بهدف التمكين من تنفيذ أنشطة التعليم والتعلم في المدارس بطريقة سلسة ومنظمة ويمكن أن تحقق أهداف التعليم التي تضاف. وكما سبق ذكره، فإن التجميع ليست مقصودة من غير أجل المتعلمين، ولكنها تهدف إلى مسـاعدتهم على أن يكونوا قادرين على التطوير قدر الإمكان. وإذا لم يته المقصيود باه من تصنيف هذه الاعتراضات فإن المتعلمين بالتالي لا يحتاجون إلى تصنيفهم أو إلى القيام بذلك. كل المتعلمين قدرة و طابع، هناك بعض الأشياء ملاحظة لمعرفة الاختلافات بين الأفراد من حيث التعلم. على الأقل ست اختلافات فردية لدى الطلبة، وهي تطوير الفكرياة، المهارات اللغوياة، وخلفيتهم، وأسلوب التعلم، والمواهب والمصالح، والشخصية (Sudjana and Rivai 2007). فوجود تصنيف المتعلمين سيكون سهلا فورا. لأنهم ليسوا متجانسا في فصل الدرس. وأن يعتمد بشكل كبير على قدرهم أداء القياس التمييزية. ففي المدرسة اختبار مستخدم هو الاختبار غير لازم أي الاختبار بطريقة قراءة القرءان لتصنيف الطلاب بطبيعتهم غير أنه ليس فيها الاختبار لتصنيف الطلاب مناسبا بخصائصهم.

\section{والثالث: المشكلة التربوية}

في تنفيذ تعليم مهارة القراءة: إدارة الفصل مهم عند التعليم في الفصل وأصبحت سؤالا في هذه

الأواخر وليست الإدارة سهولة لدى معظم المعلمين. التعلم لم يكن فعاليا على تحقيق أهداف التعلم. وقت التعليم أسـاس لترقية التربية في هذا البلد. الفصل الذي يديره المدرس حسنا سيصل إلى درجة الأعلى من أغراض التعليم. وأما الفصل الذي لاحظه الباحث تجد المظاهر، فالإدارة فيه لم يتم بما ورد في خطط التعليم وكما وصفه المدرس ألا يهتم إدارة الفصل إلا وقع فياء زحام لايدافع عملية التعليم. 
في تقويم مهارة القراءة: خلال هذا الوقت لاختبار مهاراة القراءة لدى الطلاب بقراءة سماعية فقط أي ليس لله القياس لاختبارها فهها بمواجهة بعضههم بعضا. ولكن، إذا نظرنا إلى أنواع تقويم مهارة القراءة هناك أنواع كثيرة بأشكال مختلفة. ويمكن التقويم لقياس مهارة القراءة، والنحو الصرف، والمراد وما إلى ذلك يمكن القيام باه في كل مرة، لذلك لا بمجرد كفاءة قراءتهم. في استخدام الوقت: وفقا لأحكام الوقت الذي قدمتـا وزارة الشؤون الدينية بشأن المواد العبية التي كانت في الأصل أربع ساعات للمدرسـة الثانوية الإسلامية، ولكن فيها لم تعط سوي ساعتين للدراسـة كل أسبوع. وهذا يتطلب من المعلم مزيدا من الجدية والاستفادة وقت التعليم بأكبر قدرا حتى يمكن التعليم فعالية، وبحيث تمكن أغراض التعليم متحقق حسنا.

في إدارة الفصل غير القضية: إدارة الفصل الدراسي تصبح مهماة جدا وتحدد عملية التعليم في الفصول الدراسية. وكفاءة المعلم تنبغي أن يناور حالة الدراسـة تصبح قدرا مطلقا له. فالنتائج من عرض البيانات يمكن القول بأن إدارة الفصل في القسم العاشر 2 بالمدرسة الثانوية الإسلامية سيغاسارى مالانق غير القضياة، بكثير الطلاب يتحدثون بعضهه بعضيا أثناء عملية التعليم.

علاج مشكلات تعليم مهارة القراءة في حين أن الحل والمحاولات الذي قدمه الباحث في نظرية هذه المناقشـة يشير إلى النظرية التي هي في الفصل 2. ولذلك، فإن جميع مشكلات مهارة القراءة فها ليس كل منها يمكن أن تعطي العلاج. فيمكن تطبيق النظرية المناسبة باحتياج كل مشكلات. فبيان هذه الحلول لمشكلات مهارة القراءة فيه كما يالي : العلاج للمشكاتلات اللغوية

العلاج لتقليل المشكلات اللغوية في مهارة القراءة الذي ينفذها المدرسة والمدرس اللغة العربية بشكل البرنامج لم يصل إلى المجال اللغوي أي العلاج للمشكلة غير اللغوية، لذلك يبحث الباحث محاولة ومناقشـة لحلول لهذه المشكلة. وشرحهاكما يالي :

الأول: ضعف تطبيق تركيبي النحو والصرف في نص القراءة. ويمكن أن يتم علاج ذلك عن طريق :

(1) التركيز على التطبيقات النحوية والصرفية وتزويد القارئ بالقواعد النحوية والصرفية الوظيفية؛ (2) القراءة الجهريّة المتكررة وفق برنامج مدروس ليكون الطلاب رغبة في القراءة

والثاني: عجز الطلاب عن أداء المعنى. ويمكن أن يتم علاج ذلك عن طريق: (1) التأكيد دائما على حفظ المفردات بمعاني لجميع الطلاب؛ (2) الأمر بكثرة القراءة لدى الطلبة ثم الفهم وترجمتها إلى اللغة 
الإندونيسية. قد يكون ذلك راجعا إلى عدم معرفة التلميذ أين تبدأ الجملة وأين تنتهي. وهنا يلزم التدريب علامات الترقمي من نطق وفواصل منقوطة، وفواصل بدون نطق، وأن يدرب التلميذ على أن يبدأ القراءة من بداية الجملة وألا يتوقف إلا عند الفاصل أو في نهاية الجملة. وهنا يلزم أن تكون المادة المقروءة مكتوبة بأسلوب جيد، وجمل قصيرة، وأن تكون خالية من الجمل الاعتراضية، والاستطراد كما سبق القول(مدكور 2010).

والثالث: القفز في بعض الكلمات. ويمكن أن يتم علاج ذلك عن طريق : (1) التأكيد من سلامة العين وعدم اضطراب حركتها الأفقية والرأسية، إذ يمكن إخضياء أي خلل عضيوي في العين للعلاج؛ (2) يجب إقناء القارئ بأن السرعة في القراءة مميزة، فالتأني والهدوء سمتان مميزتان للقراءة السليمة؛؛ (3) تذليل صعوبة قراءة الكلمات العريبة التي لم يسبق للقارئ أن تعرف عليها وذلك قبل الشروع في القراءة الجهرية؛ (3) تجويد الخط مع ظبط المسافات بين الكلمات على نحو منتظم؛ (4) إخيار الوقت المناسب للقراءة بحيث يكون القارئ معدا من الناحية النفسية؛ (5) وضع القواعد الموضحة لكيفية فهم الطالب للتراكيب المجازية يمكن ذلك من خلال توزيع التراكيب المجازية على الدروس ووضع التراكيب الحقيقية المقابلة لها، مع تكرارها في سياقات مختلفة، فيعلم الطالب المقابل الحقيقي للتراكيب المجازية عندما يتلقاها، كما يمكن اختيار منهج منفصل لبعض دروس البلاغة المبسطة للمرحلة التمهيدية. وقد يكون القفز عن سطر أو أكثر للأسباب السالفة الذكر ولأسباب أخرى كيفية المسافة بين السطور، وعدم انتظار الكتابة على السطر وبسبب الأجهاد والقلق والاظطراب، وعلاج هذه الظاهرة يتم بتلافي أسبابها (الشنطي 1996). وزاد على أحمد مدكور لعلاج هذه المشكلات فليجب تدريب التلميذ على التأني في القراءة والتدريب على الفهه، والدقة في القراءة (مدكور 2010).

\section{العالاج للمشككلات غير اللغوية فيه}

وإذا كانت المشكلات غير اللغوية، فالمحاولات التي يعطيها من المدرسة ومدرس اللغة العربية على النحو التالي : (1) بطريقة جمع الطلاب في فصل واحد بكفاءتهم؛ (2) بطريقة برنامج الدراسة المجموعية؛ (3) بطريقة الإدراك بالترابط في بداية التعليم؛ (4) بطريقة تخطيط التقويم الموقت.

وبعد أن يلاحظ الباحث العلاج للمشكلات غير اللغوية، فلا تستغني زيادة العلاج لهذه المشكلات كي تكون تقليلا لها في مهارة القراءة. فالزيادات تؤخذ من الكتب العربية وما أشبهها تدفع عن هذا العلاج، وشرحها كما يالي: (1) وأما من خلال الدوافح الضعيفة فعلى المعلم والطلاب مراعاة إيجاد جو هادئ خال من التواتر عند الشروع في القراءة. و إزالة أسباب القلق والخوف من نفس القارئ بطمأننته وتشجيعه؛ 
(2) وأما من جوانب التربوية أن يستخدم المعلم الطرائق المناسبة في تعليم مهارة القراءة وما يتطلب ذلك من استعمال الوسائل التعليمية المناسبة. وإعداد البارمج التعليمية من أجل رفد المعلم بالخبرات والمؤهلات التي تسـاعده على تعليم مهارة القراءة. وأن يستخدم مدرس اللغة العربية وقت التعليم وقتا فعاليا وألا يستعمله مضيعا للأنشطة الأخرى غير تعليم مهارة القراءة.

\section{خاتمة}

تنقسم مشكلات تعليم مهارة القراءة في القسم العاشر 2 المدرسـة الثانوية الإسلامية المعارف سينجاسـارى ملانق إلى قسمين : الأول المشكلات اللغوية وهي المشكلة في تطبيق تركيبي النحو والصرف أو الخطأ في ضبط الكلمات و المشكلة في فهم المقروء أو العجز عن أداء المعنى و المشكلة في قفز بعض الكلمات. الثاني المشكلات غير اللغوية وتنقسم إلى ثلاثة أقسام فهي المشكلة الاجتماعية بسبب خلفية الطلبة المختلفة، والمشكلات النفسية على الدوافع لمهارة القراءة وتجميع الطلاب، والمشكلات التربوية تشمل على تقويم مهارة القراءة، واستخدام الوقت، وإدارة الفصل غير المناسبة. والعلاج لمشكلات تعليم مهارة القراءة بطريقة تصنيف الطلاب في فصل واحد بكفاءتهم وخصائصهه، وبطريقة برنامج الدراسـة المجموعياة، و بطريقة الإدراك بالترابط في بداية التعليم، وبطريقة تخطيط التقويم.

وفقا لنتائج البحث مما سبق فعلى الباحث أن يقترح على تعليم مهارة القراءة في القسم العاشر 2 بالمدرسة الثانوية الإسلامية المعارف سينجاساري مالانق. فالمقترحات: (1) على المعلم أن يطبق علاج المشكلات اللغوية لمهارة القراءة الذي يبحثه الباحث في مناقشّة هذا البحث نظرا إلى الأعراض في عملية التعليم؛ (2) أن تجعل المدرسة البرنامج الخاص لترقية مهارة القراءة لدى الطلبة؛؛ (3) أن تجعل الاختبار اللغوي لدخول المدرسة أول مرة تصنيفا على الطبيعات والخصائص لهم؛ (4) أن ترقي كفاءة المعلم حالة الفصل حينما جرت الدراسـة.

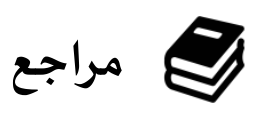

Arikunto, Suharsini. 2010. Prosedur Penelitian: Suatu Pendekatan Praktik. Jakarta: Rineka Cipta.

Asrori, Muhammad. 2008. Psikologi Pembelajaran. Bandung: Wacana Prima. 
Bungin, Burhan. 2001. Metodologi Penelitian Sosial. Surabaya: Airlangga University Press.

Crewell, Jhon W. 2013. Research Design. Yogyakarta: Pustaka Pelajar.

Gunawan, Imam. 2013. Metode Penelitian Kualitatif. Teori Dan Praktik. Jakarta: Bumi Aksara.

Hidayat, Nandang Sarif. 2012. Problematika Pembelajaran Bahasa Arab. UIN Sultan Syarif Kasim.

Imron, Ali. 1989. Manajemen Peserta Didik Di Sekolah. Malang: Jurusan Administrasi Pendidikan FIP IKIP Malang.

Moleong, Lexy J. 2007. Metodologi Penelitian Kualitatif. Bandung: Rosda.

Nasution. 2003. Metode Penelitian Naturalistik Kualitatif. Bandung: Tarsito.

Saidu, Fiddaroini. 2006. Strategi Pengembangan Pendidikan Bahasa Arab. Surabaya: Jauhar.

Sudjana, Nana and Ahmad Rivai. 2007. Teknologi Pengajaran. Bandung: Sinar Baru Algesindo.

Sukandarramidi. n.d. Metodologi Penelitian. Yogyakarta: Gadjah Mada University Prees. Sunarto. 2001. Metodologi Penelitian. Surabaya: PPS Unesa.

Wahid, Nur. 1988. Problematika PengajaranBahasa Arab. Semarang: PT. Karya Toha Putra.

$$
\begin{aligned}
& \text { الخطيب, محمد بن إبراهيم. 2003. طرائق تعليم اللغة العربية. الرياض: المملكة العربية السعودية. } \\
& \text { الشنطي, محمد صالح. 1996. المهارات اللغوية. المملكة العربية السعودياة: ار الأندلوس للنشر والتوزيح. } \\
& \text { توفيق, الخصاونة،. 2000. “المحتوى الثقافي في كتب تعليم اللغة العربية للناطقين بغيرها”. } \\
& \text { جابر, جابب عبد الحميد n.d. مناهج البحث في التوبية وعلمر النفس. القاهرة: دار النهضية العربية. } \\
& \text { شحاته, حسن. 1993. تعليم اللغة العبربية بين النظرية والتطبيق. لبنان: الدار المصرية اللبنانية. } \\
& \text { مدكور, على أحمد. 2010. طرق تلدريس اللغة العببية. عمان: ، دار المسيرة للنشر والتوزيع. } \\
& \text { ينوس, محمود. 2007. التوبية والتعليه. كونتور: مطبعة دار السلام. }
\end{aligned}
$$

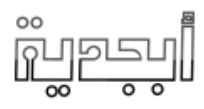

